\title{
ARTICULAÇÃO ENTRE EDUCAÇÃO BÁSICA E SUPERIOR: UMA EXPERIÊNCIA SOBRE A TRANSFORMAÇÃO DO PENSAR E AGIR DOCENTE
}

\author{
ARTICULATION BETWEEN BASIC AND HIGHER EDUCATION: \\ AN EXPERIENCE ON THE TRANSFORMATION OF TEACHING \\ THINKING AND ACTING
}

\begin{abstract}
ARTICULACIÓN ENTRE EDUCACIÓN BÁSICA Y SUPERIOR: UNA EXPERIENCIA SOBRE LA TRANSFORMACIÓN DEL PENSAR Y AGIR DOCENTE
\end{abstract}

\section{Ariane Xavier de Oliveira* Letícia Vidigal** \\ Diene Eire de Mello***}

* Pedagoga e mestranda em Educação pelo Programa de Pós-graduação em Educação do Departamento de Educação da Universidade Estadual de Londrina (UEL). Rolândia, Paraná, Brasil. E-mail: arianee.oliveira94@gmail. com

** Pedagoga e mestranda em Educação pelo Programa de Pós-graduação em Educação do Departamento de Educação da UEL. Rolândia, Paraná, Brasil. E-mail: leticia_vidigal_@hotmail.com

*** PhD em Educação com ênfase E-learning pela Universidade Aberta (UAB) de Portugal. Professora do Departamento de Educação da UEL. Londrina, Paraná, Brasil. E-mail: diene.eire.mello@gmail.com

Recebido para publicação em: 18.8.2017

Aprovado em: 10.4.2018

\section{Resumo}

Este relato de experiência delineia reflexões de uma professora de Ciências na educação básica pública do município de Londrina-PR. O estudo pautou-se pela perspectiva materialista histórica-dialética do homem, de sociedade e de conhecimento e tem como objeto a formação de professores, tendo como foco específico as possibilidades de apropriações teóricas e alterações na prática docente por meio da participação de uma professora em programa de formação continuada, denominado Observatório da Educação. As análises dos relatos da professora indicam a contribuição do programa para a transformação do seu pensar e agir.

Palavras-chave: Observatório da Educação. Obeduc. Formação continuada. Prática pedagógica.

\section{Abstract}

This report of experience outlines reflections of a teacher of Sciences in the basic public education of the city of LondrinaPR, Brazil. The study was based on the historical-dialectical materialist perspective of humans, society, and knowledge, and has as its object the education of teachers, having as specific focus the possibilities of theoretical appropriations and changes in teaching practice through the participation of a teacher in a continuing education program, called the Education Observatory. The analyzes of the teacher's reports indicate the contribution of the program to the transformation of her thinking and acting.

Keywords: Education Observatory. Obeduc. Continuing education. Pedagogical practice. 


\section{Resumen}

Este relato de experiencia delinea reflexiones de una profesora de Ciencias en la educación básica pública del municipio de Londrina-PR, Brasil. El estudio se basó en la perspectiva materialista histórica-dialéctica del hombre, de sociedad y de conocimiento y tiene como objeto la formación de profesores, teniendo como foco específico las posibilidades de apropiaciones teóricas y alteraciones en la práctica docente por medio de la participación de una profesora en programa de formación continuada, denominado Observatorio de la Educación. Los análisis de los relatos de la profesora indican la contribución del programa para la transformación de su pensar y actuar.

Palabras clave: Observatorio de la Educación. Obeduc. Formación continua. Práctica pedagógica.

\section{Introdução}

O presente trabalho propõe-se a analisar em que medida a participação docente em projeto de pesquisa científica possui potencial para transformar concepções e práticas pedagógicas na realidade escolar. Para tanto, busca delinear reflexões acerca da experiência de uma professora da disciplina de Ciências, atuante na educação básica pública do município de Londrina-PR e participante como bolsista do subprojeto de pesquisa científica "A práxis pedagógica: concretizando possibilidades para a avaliação da aprendizagem", desenvolvido no Departamento de Educação da Universidade Estadual de Londrina (UEL).

Esse subprojeto de pesquisa integra o Observatório da Educação (Obeduc), um programa financiado pela Coordenação de Aperfeiçoamento de Pessoal de Nível Superior (Capes) e cujos objetivos são proporcionar a formação inicial e continuada de docentes, intervir na realidade das escolas públicas com baixo Índice de Desenvolvimento da Educação Básica (Ideb) e, além disso, fomentar a produção de pesquisas educacionais.

O programa Obeduc encerrou-se em fevereiro de 2017 e, nos dois últimos anos de seu desenvolvimento, empreenderam-se ações universitárias para o aprimoramento do conhecimento teórico dos professores da educação básica junto aos estudantes de Pedagogia, mestrandos e doutorandos em Educação. Desse modo, os envolvidos no programa puderam vivenciar ações de planejamento conscientes, isto é, almejaram a organização do trabalho pedagógico docente com base nas concepções de educação, ensino e aprendizagem discutidos, e, além disso, buscando, por meio da escolha das estratégias didáticas, a construção dos conhecimentos científicos dos educandos das escolas participantes.

Sendo assim, a presente investigação trata de um relato de experiência fruto das atividades pedagógicas compreendidas no período de fevereiro de 2015 a fevereiro de 2017, instigada pelos seguintes questionamentos: a participação docente em 
projeto de pesquisa científıca mobiliza a transformação do pensar e agir pedagógico no cotidiano escolar? Em que medida essa participação propicia novos pensamentos e formas de perceber a própria prática pedagógica?

Em busca de reflexões sobre as questões levantadas, a fundamentação teórica do presente texto se apoia: no Materialismo Histórico e Dialético, base filosófica na qual o homem é compreendido como um ser social, cuja humanidade provém da cultura (LEONTIEV, 1978, p. 261); na perspectiva sócio-histórica, a qual abrange a Teoria Histórico-Cultural, uma vertente da psicologia desenvolvida na União Soviética em meados do século 20 por Lev S. Vygotsky e seus colaboradores Alexei Nikolaievich Leontiev e Alexander Romanovich Luria; e na Pedagogia Histórico-Crítica, vertente que contribui com a reflexão sobre a transmissão e a apropriação do conhecimento científico no seio da prática social global.

A materialidade

histórica possui

repercussões no

pensamento e na

prática social

e educativa

A educação escolar, a partir do referencial teórico supracitado, é compreendida como elemento de papel singular aos integrantes das instituições educacionais, o qual se traduz em proporcionar a apropriação dos instrumentos que possibilitam aproximar-se do saber elaborado, sistematizado, bem como o próprio acesso aos rudimentos desse saber (SAVIANI, 2011). Para tanto, os programas de fomento ao desenvolvimento de pesquisas em educação podem contribuir com a superação de práticas pedagógicas ainda muito dissonantes dos estudos provenientes do meio acadêmico, o que pode resultar na diminuição da distância comumente observada entre a pesquisa e a prática educativa, isto é, entre a universidade e a escola de educação básica.

Conforme salientado, no caso específico do programa Obeduc, em virtude do seu propósito maior de mobilizar novas práticas de ensino nas instituições com baixo Ideb, voltadas à superação dos índices das avaliações externas, investiu-se no processo formativo de uma professora de Ciências da rede básica, bolsista do programa. Por conta disso, após os momentos de formação proporcionados pelos encontros do subprojeto e da concretização da "nova" ação pedagógica na realidade escolar, a professora $Y^{1}$ relatou suas percepções, aprendizagens e considerações a partir de sua primeira participação em um projeto de pesquisa universitária. Para tanto, a seguir estão o percurso da experiência vivenciada e os relatos da professora Y em conjunto à discussão teórica.

\section{Metodologia: o percurso da experiência}

O presente estudo buscou assumir como referencial teórico a concepção materialista histórica-dialética do homem, de sociedade e de conhecimento. A partir de tal perspectiva, a prática social é a síntese de múltiplas determinações. Todas as ações e proposições no decorrer da prática investigativa se pautaram pela compreensão da totalidade e da realidade concreta. Dessa forma, a materialidade histórica possui repercussões no pensamento e na prática social e educativa. 
Portanto, a partir de tal pressuposto, entre maio e julho de 2016, foram realizadas intervenções pedagógicas com base nos estudos teóricos, em uma turma composta por 21 alunos do ensino fundamental de uma instituição que atende os anos finais do ensino fundamental e o ensino médio, situada em um bairro periférico na zona sul do município de Londrina-PR. Além dos estudantes, a experiência contou com a participação de uma professora da educação básica, uma professora da universidade e uma estudante de Pedagogia, esta última acompanhou o processo de execução por meio de observações.

Importante salientar que as análises alicerçadas especificamente nesse texto tiveram como fonte de dados os relatos escritos da docente da educação básica com base na vivência do conjunto dos seguintes elementos: os momentos de formação, planejamento, execução e avaliação da prática pedagógica. Todavia, as descrições dos elementos envolvidos fizeram-se necessários para melhor contextualização do fenômeno. Assim, o presente estudo consiste em pesquisa de delineamento qualitativo, caracterizando-se como estudo descritivo.

Por compreender o contato com a realidade investigada, a pesquisa qualitativa mostrou-se pertinente, visto que pressupõe a obtenção de dados a partir do contato estabelecido entre o pesquisador e o ambiente natural a ser explorado; utiliza-se dos dados descritivos, fundamentais a uma caracterização consistente e fiel, capaz de facilitar a compreensão do problema estudado; enfatiza mais o processo do que o produto, verificando como a sua indagação está sendo retratada nas atividades e interações grupais; além de buscar abordar a perspectiva dos participantes (LUDKE; ANDRÉ, 1986).

A partir das vivências compreendidas no período de fevereiro de 2015 a fevereiro de 2017, nas quais se incluíram os momentos de estudos, elaboração das intervenções e posterior análise dos dados alcançados, a professora $Y$ relatou por escrito suas percepções, aprendizagens e considerações, quando pôde organizar e efetivar um ensino intencional que viabilizasse aos estudantes a percepção dos sentidos e significados de determinado conhecimento para a vida social, ou seja, um trabalho pedagógico que oportunizasse ao estudante a percepção da relevância da aprendizagem do conteúdo científico e pudesse usufruir do mesmo em seu cotidiano, por meio da mudança de ações e desta forma, gerasse a modificação da realidade em que se encontra.

\section{Trabalho, educação e ação docente}

Asbahr (2005), quando disserta sobre a significação social da atividade pedagógica do educador, enfatiza que cabe a este intencionar situações propiciadoras da aprendizagem a partir dos conteúdos científicos a serem transmitidos e a melhor maneira de fazê-lo. Logo, a significação social da atividade pedagógica consiste 
na garantia da apropriação do conhecimento não cotidiano por meio do trabalho pedagógico. Conforme a autora, a compreensão da significação social da atividade pedagógica é fundamental para descobrir o que motiva a atividade docente, ou seja, qual é o sentido pessoal da atividade docente para o professor. Isto porque a possivel distância entre significado e sentido pessoal no trabalho docente pode influenciar o produto do trabalho do educador, consequentemente, inferindo na qualidade da educação.

Toda ação educativa é permeada pela personalidade do educador, posto que o ato de educar pressupõe um posicionamento político e pedagógico, uma ação intencional e tomada de decisões. A personalidade do educador, por sua vez, é constituída essencialmente pelas relações de produção e trabalho (MARTINS, 2015). Por meio do trabalho, atividade precípua na satisfação das necessidades de subsistência dos sujeitos, o indivíduo adquire a possibilidade de formar-se e desenvolver-se como ser genérico, representante do gênero humano, ao passo que pode se apropriar da atividade humana objetivada no mundo da cultura pelas gerações precedentes (SAVIANI; DUARTE, 2012).

Toda ação educativa é permeada pela personalidade do educador
Ocorre que, na sociedade capitalista, o trabalho, embora produza riquezas objetivas e subjetivas, isto é, materiais e imateriais, não possibilita que as mesmas possam ser apropriadas por aqueles que trabalham, dado que toda essa riqueza passa a ser posta a serviço do capital, e não mais à totalidade dos seres humanos (SAVIANI; DUARTE, 2012). Com isso, há uma cisão entre o trabalhador e o produto de seu trabalho, ou seja, um esvaziamento do homem para com os outros e para consigo mesmo, o que resulta no esvaziamento de sua própria personalidade (MARTINS, 2015). Nesse sentido, o trabalho educativo precisa ser pensado como "[...] um processo que devolve ao homem a sua própria personalidade, isto é, a sua qualidade de agente da história que [...] modifica [...] as condições exteriores [e] a si mesmo" (MARTINS, 2015, p. 135).

Tais reflexões permitem pensar o exercício docente de cada sujeito que, permeado pelas condições sociais, históricas e culturais de seu trabalho, tem sua personalidade, sua pessoa humana, influenciada e formada. A experiência docente, objeto de reflexão deste estudo, instaurou-se com a inserção da Professora Y no programa de formação continuada Obeduc na UEL e, posteriormente, com a sua efetiva participação no subprojeto, traduzida nos momentos de grupos de estudos, planejamento das intervenções e na execução das propostas pedagógicas. Nesse cenário, conhecer um pouco de sua trajetória histórica de formação mostra-se relevante.

Importante salientar que a formação de professores não pode ser tratada de forma estanque, como fator único e capaz de promover alterações e avanços nas práticas educativas. Como afirma Gatti (2010), a preocupação com a formação não quer dizer reputar apenas ao professor e à sua formação a responsabilidade sobre o desempenho atual das redes de ensino, múltiplos fatores convergem como: 
as políticas educacionais postas em ação, o financiamento da educação básica, aspectos das culturas nacional, regionais e locais, hábitos estruturados, a naturalização em nossa sociedade da situação crítica das aprendizagens efetivas de amplas camadas populares, as formas de estrutura e gestão das escolas, formação dos gestores, as condições sociais e de escolarização de pais e mães de alunos das camadas populacionais menos favorecidas (os "sem voz") e, também, a condição do professorado: sua formação inicial e continuada, os planos de carreira e salário dos docentes da educação básica, as condições de trabalho nas escolas (GATTI, 2010, p. 1359).

No caso específico da experiência relatada, alguns dos problemas apontados permeiam a realidade vivenciada pela professora Y. Consoante ao Projeto Político-Pedagógico (COLÉGIO ESTADUAL THIAGO TERRA, 2011) da instituição escolar pública onde o trabalho da professora $Y$ se materializa entre a multiplicidade de fatores condizentes ao exposto por Gatti (2010), destaca-se uma comunidade escolar de perfil econômico menos abastado, com famílias cuja renda é formada somente pela Bolsa Família. Quanto à escolaridade, o número de pessoas com formação básica até a $8^{a}$ série é pequeno, predominando um índice de analfabetos de 12\%. Muitas famílias não possuem bens (motos, carros, eletrodomésticos) nem energia elétrica em casa para gerar o comprovante de residência para matrícula na instituição de ensino. A rotatividade de professores é um fator preponderante na instituição. Aliado a isso, também se apresenta um alto índice de evasão e a reprovação, culminando dessa forma com um baixo Ideb. Além disso, problemas sociais relativos a comercialização e consumo de drogas, bebida alcoólica e gravidez na adolescência compõem a realidade.

0 exercício inicial

na docência foi

oportunizado

pelos estágios obrigatórios

do curso

Com base no breve contexto apresentado, este artigo abordará a trajetória da professora $Y$, participante deste estudo. Seu ingresso na carreira ocorreu no ano de 1993, ao cursar Licenciatura em Ciências e Matemática, em faculdade privada, no período noturno. A começar deste período, o exercício inicial na docência foi oportunizado pelos estágios obrigatórios do curso. Tem-se, hoje, que a carga horária posta tem como finalidade "[...] proporcionar aos licenciandos um contato mais aprofundado com as escolas de educação básica, de forma planejada, orientada e acompanhada de um professor-supervisor de estágio" (GATTI, 2014, p. 40).

Conforme a participante, pela necessidade de manutenção financeira da graduação, o trabalho durante o dia em outra área foi necessário. Tal situação enfatizada por ela a impossibilitou de participar de projetos para aprofundar-se no universo da pesquisa acadêmica. Tal fato ainda é a realidade de muitos estudantes da área da Educação, que precisam trabalhar em horário inverso, até mesmo em outras áreas, para pagar os estudos, sendo privados da participação em outras atividades acadêmicas, as quais, do ponto de vista formativo, contribuem para o enriquecimento do preparo profissional. 
Neste aspecto específico, há de se pensar as condições materiais e intelectuais de acesso às universidades públicas existentes aos filhos da classe trabalhadora, tendo em vista que nos dados presentes nos

[...] resumos técnicos do Censo da Educação Superior de 2009, 2010 e 2011, disponibilizados pelo Ministério da Educação (MEC) e pelo Instituto Nacional de Estudos e Pesquisas Educacionais Anísio Teixeira (Inep) (BRASIL, 2013a, b e c - últimos dados mais detalhados disponíveis), observa-se que a grande maioria dos cursos e das matrículas em licenciaturas está nas instituições privadas de ensino superior [...] (GATTI, 2014, p. 36).

É, contudo, por meio dos elementos da pesquisa, que se vislumbra a possibilidade de reflexão e problematização do fazer pedagógico e da ação educativa na sociedade atual vigente. À vista disso, verifica-se a importância da pesquisa-ação, especificamente aos educadores que, em seu campo profissional, precisam agir pautados no conhecimento epistemológico e buscar constantemente melhores formas de possibilitar aos sujeitos do processo educacional um ensino de qualidade. Thiollent (1985, p. 14 apud GIL, 2008, p. 30) define a pesquisa-ação como aquele tipo de pesquisa que é "[...] concebida e realizada em estreita associação com uma ação ou com a resolução de um problema coletivo [...]", e os envolvidos com a situação "[...] estão envolvidos de modo cooperativo ou participativo".

Ainda se tratando de aspectos fundamentais à formação docente, pesquisas mencionadas no estudo de Gatti (2014, p. 39) apontam que, no Brasil,

[...] os cursos de licenciatura mostram-se estanques entre si e, também, segregam a formação na área específica dos conhecimentos pedagógicos, dedicando parte exígua de seu currículo às práticas profissionais docentes, às questões da escola, da didática e da aprendizagem escolar. Isso denota desconsideração da Resolução no 01/2002 do Conselho Nacional de Educação (BRASIL, 2002 apud GATTI, 2014, p. 39).

Estes destaques corroboram os relatos da professora $Y$, ao apontar que, embora o curso superior realizado fosse voltado à formação de professores e ter contemplado aulas como didática, psicologia para educação, prática de ensino de ciências e matemática e estrutura e funcionamento do ensino da escola básica, os conteúdos de cunho pedagógico não foram explorados de maneira a suscitar e contribuir para reflexões e desenvolvimento de possíveis práticas conscientes em seu fazer docente. Novamente, com apoio no estudo de Gatti (2014, p.39), para o confronto com a narrativa da professora $Y$, quando pontuou acerca dos aspectos didático-pedagógicos do seu processo formativo:

A formação para a prática da alfabetização e iniciação à matemática e às ciências naturais e humanas é precária, como também é precária a formação para o trabalho docente nos anos finais do ensino fundamental e no ensino médio. Há quase ausência nesses cursos de formação em conhecimentos sobre o desen- 
volvimento cognitivo e socioafetivo de crianças, adolescentes e jovens, suas culturas e motivações. De modo geral, nas ementas dos currículos das licenciaturas encontram-se, nos fundamentos educacionais, proposições genéricas que passam ao largo de oferecer uma formação mais sólida. Há muito descompasso entre os projetos pedagógicos desses cursos e a estrutura curricular realmente oferecida. Nesta, observa-se claramente a ausência de integração formativa na direção de um perfil profissional de professor para atuar na educação básica (GATTI; NUNES, 2009; GATTI et al., 2010a; LIBÂNEO, 2010; GATTI, 2012; PIMENTA; LIMA, 2007 apud GATTI, 2014, p. 39).

Assim sendo, é notório nos cursos de licenciatura como disciplinas voltadas às formas de ensino são colocadas em segundo plano e se dá certa relevância ao valor dos conteúdos específicos do curso, ofertando "[...] apenas um verniz superficial de formação pedagógica e de seus fundamentos que não pode ser considerado como realmente uma formação de profissionais para atuar em escolas na contemporaneidade" (GATTI, 2014, p. 39).

Apesar disso, não se pode perder de vista que "[...] todo objeto, todo fenômeno tem não só um conteúdo, mas também uma forma [...]”, e esta forma constitui-se como a "[...] organização interna, a estrutura do conteúdo, que torna possível a sua existência. A forma e o conteúdo formam unidade" (SPIRKIN; YAKHOT, 1975, p. 160). Saviani (2003, p. 75), assinala que "[...] a questão central da pedagogia é o problema das formas, dos processos, dos métodos; [que] só fazem sentido quando viabilizam o domínio de determinados conteúdos".

Outro aspecto evidenciado no discurso da professora $Y$ merece atenção. A equívoca compreensão acerca dos conceitos teoria e prática e, discursos como "na prática, a teoria é outra" ou "dado curso é muito teórico", permeiam certos diálogos no interior dos corredores escolares e acadêmicos. Ao discorrer acerca do contato que teve, em 2003, com alguns conteúdos relativos a pesquisas educacionais e os pressupostos teóricos em um curso de especialização em gestão escolar, a professora $Y$ afırmou: "[...] nesse caso, ficou somente em teoria, não tive práticas, e eu também não tentei pôr em prática as teorias que estava estudando, achava que essas teorias deveriam ficar ali, onde estavam, no papel".

A fala da professora parece demonstrar o que já temos vivenciado no tocante à dicotomia teoria e prática, pela forma como são tratadas em vários cursos e especificamente nas licenciaturas. De acordo com Saviani (2007), é recorrente a oposição entre teoria e prática na educação. É preciso compreender que teoria e prática são aspectos distintos, mas é necessário tomá-los sob uma compreensão dialética, de que ainda que distintos, são inseparáveis, definindo-se e caracterizando-se um em relação aos outros. Esclarecendo, o autor diz:

A prática é a razão de ser da teoria, o que significa que a teoria só se constituiu e se desenvolveu em função da prática que opera, ao mesmo tempo, como seu fundamento, finalidade e critério de 
verdade. [...] Assim, sem a teoria, a prática resulta cega, tateante, perdendo sua característica específica de atividade humana (SAVIANI, 2007, p. 108).

A professora, não obstante, relata esta questão ocorrida quando se inseriu no grupo de pesquisa do Obeduc:

Quando comecei a participar do Obeduc, a ouvir falar sobre os fundamentos teóricos, da busca do desenvolvimento humano para que se tenha uma transformação dos conhecimentos científicos e entender o desenvolvimento dos sentidos para compreender o processo de aprendizagem. No primeiro momento, fiquei um pouco descrente, pois estavam ainda muito enraizadas em mim velhas práticas [...]. Comecei a me dar conta de que estas velhas práticas utilizadas por quase 19 anos começaram a me angustiar. Cheguei a pensar que 'nada sabia' que havia errado por todos estes anos, trabalhando de uma forma preocupada com as atividades e conteúdos, sem adotar fundamentos teóricos para minhas práticas pedagógicas. No início de minha participação, todas as falas e discussões me pareciam utópicas. Ou seja, discurso de professor universitário, que conhece com profundidade uma infinidade de teorias, mas desconhece o chão da escola (PROFESSORA Y).

Dito isto, aproxima-se o ponto crucial do texto: as contribuições do programa Obeduc na formação continuada da Professora Y. Assim, busca-se, entre outros aspectos, rever-se essa falsa dicotomia, por meio do desenvolvimento de estudos teóricos e organizações do ensino na perspectiva dialética, no sentido de pensar esses conceitos como elementos de uma totalidade. Elementos estes que se relacionam e se interferem mutuamente. Os posteriores relatos da Professora $Y$ dão indicativos do quanto suas concepções se alteraram por meio das vivências e reflexões proporcionados pela formação continuada a qual acessou.

\section{Outros achados da experiência: a transformação do pensar e agir docente}

Todo programa

de formação tem

como objetivo

alterações na

realidade
Os momentos de formação proporcionados pelos encontros do subprojeto "A práxis pedagógica: concretizando possibilidades para a avaliação da aprendizagem" foram conduzidos no sentido de auxiliar os professores, dentre eles a Professora Y, a elaborarem uma proposta didática, ou seja, uma sequência de atividades voltadas ao desenvolvimento humano por meio do acesso a um conteúdo específico. Sendo assim, foram necessários momentos de discussões, estudos e diálogos que possibilitassem reflexões na tentativa de compreender o contexto escolar, o público-alvo da disciplina, a organização do ensino e as estratégias didáticas para alcançar os objetivos que viriam a ser traçados para alterar as práticas de ensino.

Faz-se importante ressaltar que todo programa de formação tem como objetivo alterações na realidade. Portanto, o grupo de professores da universidade tomou 
como hipótese válida que a participação da professora nos grupos de estudos provocaria alterações na sua forma de pensar seu trabalho e, portanto, a prática também sofreria alterações qualitativas. Entretanto, a realidade concreta e objetiva é mais complexa e profunda e a fragmentação entre teoria e prática ainda é um elemento a ser olhado com permanente vigilância pelos pesquisadores.

A Professora $Y$ participou ativamente de todas as atividades no âmbito do projeto Obeduc. De acordo com o Projeto Político-Pedagógico (COLÉGIO ESTADUAL THIAGO TERRA, 2011), a instituição apresenta alguns problemas, como: uso e comercialização de drogas, consumo de bebidas alcoólicas, violência e gravidez na adolescência. Além disso, cenas de violência são recorrentes no bairro, que inevitavelmente acabam afetando o ambiente escolar, realidade muito parecida com boa parte das grandes cidades do Brasil.

Em relação ao quadro de docentes, este se apresenta quase sempre incompleto, devido à alta rotatividade de professores, sendo que entre os aspectos mais citados está a excessiva violência no bairro, impulsionada pelo consumo de drogas. Nessa perspectiva, Lapo e Bueno (2003) realizaram uma pesquisa que aborda a questão do abandono do magistério público na rede de ensino do estado de São Paulo. A análise dos dados qualitativos obtidos por meio de um questionário enviado a 158 ex-professores e 16 entrevistas sobre histórias de vida profissional apontou a questão salarial como o principal motivo de abandono do magistério. Embora tenha sido o motivo mais citado, os autores destacam que na maioria dos casos, a resposta esteve acompanhada de razões referentes a falta de perspectivas de crescimento profissional e péssimas condições de trabalho, aspectos decorrentes do modo como o estado gere a educação e o ensino público (LAPO; BUENO, 2003, p. 73). Em suma, para além dos baixos salários, que contribuem para o desencanto em relação à profissão, também o modo de organização do sistema educacional, suas precárias condições, a insatisfação no trabalho e o desprestígio profissional colaboram para tal fato.

Ao que se refere ao baixo índice do Ideb apresentado na Instituição, o Projeto Político-Pedagógico (COLÉGIO ESTADUAL THIAGO TERRA, 2011) apresenta como justificativas as frequentes repetências e a evasão escolar. O documento também menciona o atendimento de estudantes em situação de risco, bem como enfatiza que a maioria dos alunos do $6^{\circ}$ ano chegam despreparados para a série. Outro aspecto que exerce influência no trabalho pedagógico é a precária infraestrutura, apontando necessidade de uma reforma no colégio, pois em dias de chuva há o alagamento de diferentes espaços, impossibilitando o uso dos mesmos.

Nessa lógica, a Professora $Y$ descreve que a escola em questão se encontra em um prédio emprestado. Os espaços da instituição são restritos, como o pátio e a biblioteca, por exemplo. Afırma ainda que para explorar a disciplina de Ciências não há laboratório para tal disciplina. Tais fatos, de acordo com sua ótica, dificultam o trabalho diferenciado com os alunos para além do espaço da sala de aula, con- 
sequentemente, impossibilitando outras estratégias didáticas. Em relação a esse aspecto, relata: "sempre é muito difícil, o que muitas vezes usamos como desculpa para não variar as nossas aulas, já que muitas das vezes o barulho atrapalha outras salas" (Professora Y).

Todavia, após a formação continuada, o argumento citado pela professora por diversas vezes vai perdendo força no decorrer de sua participação, que passa a ceder lugar a um esforço de repensar o seu trabalho. Neste sentido, a professora passou a compreender que

[...] barreiras como essas foram, durante o desenvolvimento das atividades, derrubadas, já que não é o espaço que temos ou a falta de laboratório que nos impede de contextualizar os conteúdos abordados, e sim falta de preparo e até tempo para buscar alternativas [...] (PROFESSORA Y).

Importante salientar que a infraestrutura adequada para o desenvolvimento de atividades diferenciadas com os estudantes é fundamental, conforme citado acerca da necessidade de um laboratório de ciências na escola e da ampliação da biblioteca. Retomando os pressupostos deste estudo, é fundamental um olhar aguçado para a realidade do professor. Todavia, a falta de laboratório e de infraestrutura não podem ser tomados como forma de justificar a escassez de experiências didáticas significativas pelos estudantes. O que está em pauta, e foi apreendido pela docente, refere-se à emergência de uma prática pedagógica fundamentada cientificamente e dotada de sentido e significado para a formação humana e atuação social dos estudantes. Ressalta-se que é a intencionalidade do educador que guiará a escolha das estratégias possíveis para o alcance dos objetivos traçados.

Outro aspecto relacionado à instituição, além da ausência de espaço físico, reside no quesito financeiro. Segundo a Professora $Y$, verbas e materiais são raros e, por vezes, impedem o desenvolvimento de outras propostas, sinalizando, assim, alguns obstáculos. Porém, para execução da nova prática pedagógica, esses obstáculos foram amenizados, haja vista que o programa Obeduc oportunizou suporte financeiro para a obtenção de recursos necessários relacionados a materiais escolares, como: lápis, borrachas, canetas, lápis de cores, cartolina, sulfites, impressões de material de apoio dos estudantes, entre outros. Além disso, o Obeduc dispôs de verbas para custear bolsas para os professores da educação básica e demais estudantes da universidade inseridos no projeto. Por isso:

Planejar uma aula sem ter a preocupação se terá ou não materiais disponíveis é de fato uma grande ajuda, pois vi que esse fato, juntamente com espaço físico, não é desculpa para não diversificar seu modo de trabalhar, gasta-se um pouco mais de energia para buscar meios alternativos, mas é possível desde que se disponha a fazê-lo (Professora Y).

À vista da breve contextualização supracitada da realidade, foram realizadas as intervenções em uma turma formada por 21 alunos do $6^{\circ}$ ano. Para tanto, o conteúdo 
previsto no plano de trabalho docente tratou do conceito científico "solo". Elegeu-se a necessidade de organização de um ensino que viabilizasse aos estudantes a percepção dos sentidos e significados de determinado conhecimento para a vida social, ou seja, que o estudante percebesse a relevância da aprendizagem do conteúdo e pudesse usufruir do mesmo em seu cotidiano, por meio da aprendizagem de novas ações, e, dessa forma, a modificação da sua realidade.

Com base nesse contexto e a partir dos relatos da Professora $Y$, organizar o ensino do conceito científico solo envolveu três aspectos que contribuíram para a ampliação do conhecimento da realidade, para a transformação do pensamento da professora e por último, para a mudança de ações didáticas e pedagógicas, que serão expostos a seguir.

O primeiro aspecto desafiador foi o planejamento, haja vista que este compõe uma das condições fundamentais para a alteração da concepção da professora de Ciências quanto ao seu papel na sala de aula e o papel do estudante, em consonância à Teoria Histórico-Cultural. Isto porque, conforme os relatos da professora em questão, sua prática pedagógica era divergente da proposta defendida pelo subprojeto. Segundo a docente, o seu fazer pedagógico permaneceu estático ao longo dos anos, com ações próximas à figura do professor enquanto um detentor do conhecimento e, o estudante, um receptor passivo. Por isso, sua prática pouco se aproximava de possibilitar a participação do estudante no processo de ensino e aprendizagem, já que, em seu ponto de vista, a preocupação de muitos professores reside em dar aulas, esquecendo de buscar atualizações, ou seja, o fazer docente não se altera ao longo do tempo. Como justificativa a esse respeito, na perspectiva da professora, tem-se que os professores não possuem tempo para buscar alternativas ou têm medo do que é novo. Assim, o uso de novas práticas e metodologias foge do cotidiano da docência.

O segundo fator foi a escolha de estratégias didáticas para que o estudante pudesse aprender, uma vez que ao abordar o ensino de conceitos científicos, a atividade educativa necessita considerar o ensino de um "[...] conhecimento dotado de características específicas [...]" que valorize a "[...] dialética entre forma e conteúdo, não se tratando de um ensino 'verbalista e abstrato' [...]”, pois as funções psíquicas só se desenvolvem no exercício de seu funcionamento por meio de atividades que as promovam (MARTINS, 2013, p. 276). A esse respeito, a Professora Y explica:

[...] até começar a participar do Obeduc, utilizava formas mais tradicionais, aliás, até então não me preocupava com qual tendência estava trabalhando, observava o que dava certo em certas aulas e mantinha, não tentava mudar.

A fala da professora $Y$ demonstra que não havia clareza das concepções de educação, ensino e aprendizagem na organização de suas ações, tais como se defendia no projeto de pesquisa para fins de planejamento e organização da sequência didática. O uso de formas mais tradicionais, às quais a professora se refere, concerne ao 
total domínio do conteúdo restrito ao professor e da organização da turma para o desempenho das atividades. 0 "dar certo" em uma aula residia no controle comportamental da turma, abordagem de todos os conteúdos propostos, com o professor como figura central do processo, a perder de vista o desenvolvimento das funções psicológicas propiciado pela apropriação dos conteúdos científicos. A partir disso, a escolha pelas formas de propiciar a aprendizagem ativa do estudante, a interação entre os sujeitos e o objeto de estudo, a colaboração, leitura, análise e comparação da realidade social, assim como proporcionar significado e relevância ao conteúdo a ser discutido demandaram reflexões e estudos.

Os relatos da docente em questão revelaram que a falta de fundamentos teóricos e a aversão por diferentes estratégias didáticas, relacionadas às concepções de homem, ensino e aprendizagem, podem ser castradoras no processo de ensino e aprendizagem. A esse respeito, Vasconcellos (1999, p. 24 apud ASBAHR, 2005, p.115) discorre que na ausência de clareza quanto à finalidade da educação, qual ideal de homem formar, para qual sociedade viver, etc., que orientam a intencionalidade do professor e também, a ausência de clareza sobre os aspectos didático-pedagógicos inerentes ao trabalho pedagógico docente, há o esvaziamento do domínio e compreensão dos vários aspectos da tarefa educativa, contribuindo para a alienação docente.

O terceiro aspecto desafiador envolveu o hábito de planejamento diário das aulas. A forma de organizar as aulas pela docente era bimestral, não se tinha o exercício de reflexão e delineamento de objetivos por aula, o que era necessário para a proposta didática.

A diferença entre objetivos gerais e específicos foi debatida. Os questionamentos sobre "o que ensinar?", "para que ensinar?" "como ensinar?" "como verificar se o estudante compreendeu?" foram constantes em cada encontro de elaboração da proposta, elegendo a importância da intencionalidade no processo educativo.

Buscar atividades dentro do conteúdo que tivessem uma significância dentro da realidade do aluno; creio que foi a parte mais difícil para mim. Tive que sair da minha zona de conforto, não só as atividades foram difíceis, mas encontrar os objetivos para cada aula também se mostrou uma tarefa nada fácil, não estive sozinha nesse processo, estive ao lado da aluna de graduação $\mathrm{H}$ [bolsista do projeto, estudante de Pedagogia que esteve auxiliando a professora em todas as etapas do projeto], que me ajudou muito na realização das atividades, posso até dizer que aprendi mais com ela do que ela comigo (PROFESSORA Y).

Assim, a partir do domínio do conteúdo a ser ensinado e da valorização da realidade em questão, considerou-se fundamental vincular o ensino do conceito científico solo ao contexto do bairro habitado pelos estudantes, atendendo a necessidade de desafiar o aluno a buscar explicações científicas aos fatos cotidianos, e não somente a simples reprodução dos conceitos científicos apreendidos na escola. 
Fiquei impressionada com o envolvimento e a participação dos alunos, como eles se dedicaram. Quando compreenderam o processo dos trabalhos, seus envolvimentos aumentaram e a coletividade ficou mais evidente e pude ser testemunha da assimilação verdadeira dos conteúdos abordados. Isso se mostrou muito prazeroso (PROFESSORA Y).

Com isso, ao almejar uma nova prática pedagógica em sua realidade, a Professora Y transformou o seu pensar frente à missão de possibilitar aos seus estudantes o acesso aos conteúdos científicos, dado que esse acesso compõe a via primordial para uma formação que possibilite ao indivíduo compreender o mundo, adquirir as formas de conhecimento, e assim, possibilitar a ampliação dos recursos cognitivos (SFORNI, 2004).

\section{Considerações finais}

Com base na descrição das finalidades e das ações envolvidas pelo programa Obeduc, e, sobretudo, no objetivo deste relato de experiência, analisar em que medida a participação docente em projeto de pesquisa científica possui potencial para transformar concepções e práticas pedagógicas na realidade escolar, tornaram-se possíveis as considerações a seguir.

O processo formativo vivenciado explorou concepções de educação, desenvolvimento humano, ensino e aprendizagem que auxiliaram a escolha consciente das estratégias didáticas, as quais contribuíram para a apropriação dos conteúdos científicos e o desenvolvimento cognitivo dos envolvidos pelos processos de ensino e aprendizagem.

Com base nos dados coletados, pode-se inferir que as ações desenvolvidas pelo programa Obeduc contribuíram para a transformação do pensar e do agir da professora Y em sua atuação na educação básica. Isto porque, partindo das condições históricas, materiais e sociais, assim como do processo formativo da professora Y e de sua prática de ensino no interior da escola participante, o programa buscou subsidiar ações que oportunizassem a percepção e a compreensão da relevância do conhecimento teórico como elemento dissonante da prática pedagógica na busca pela transformação da realidade vigente.

A transformação do pensar e do agir da professora $Y$ foi representada por meio de suas apropriações e percepções relacionadas à nova experiência pedagógica, a qual teve oportunidade planejar, refletir, organizar e efetivar em sua sala de aula. Destaca-se que a professora considerou sua nova prática pedagógica como um caminho que a conduziu para a crença e a constatação de que é possível despertar nos estudantes o envolvimento dos mesmos no processo de aprendizagem. Pois ao almejar a educação em conformidade com o referencial teórico estudado, outros caminhos e ações se fizeram necessários. 
É possível considerar também que a formação empreendida pelo programa Obeduc aos professores auxiliou a compreensão de que o significado do trabalho docente é formado pela finalidade da ação de ensinar, ou seja, pelo seu objetivo e pelo conteúdo concreto efetivado por meio das operações realizadas conscientemente pelo professor, a partir das condições reais e intencionais na condução do processo de apropriação do conhecimento científico pelo estudante.

Desse modo, com base nos relatos e nos fundamentos teóricos, pode-se destacar que a experiência vivenciada gerou motivação para a professora $Y$, isto é, um sentimento que contribui para o desencadeamento de novas práticas, apoiando-se em seus conhecimentos apropriados por meio do projeto em questão. Portanto, os programas de formação continuada de educadores, como o Obeduc, compõem vias eficazes para propiciar o desenvolvimento de práxis educativas, ou seja, contribuem com o movimento de ações, reflexões e discussões em direção à especificidade do ato educativo e, consequentemente, à valorização da educação como processo de humanização do outro.

Nesse processo de aprendizagem e reconhecimento de outros caminhos didáticos a favor do desenvolvimento humano dos envolvidos nos processos de ensino e aprendizagem, não se pode perder de vista as condições materiais e históricas condicionantes da experiência desta professora. Infelizmente, ainda não são todos os professores que dispõem de tempo, condições financeiras e oportunidades para participar de processos formativos com maior duração, envolvendo estudos teóricos e práticas, tal qual relatado pela professora Y. Enquanto classe trabalhadora, a formação continuada docente consoante às necessidades do cotidiano escolar, bem como as condições mínimas de trabalho como infraestrutura e materiais, devem permear as reivindicações desses profissionais aos poderes públicos governamentais.

Por fim, ressalta-se aqui o potencial e a necessidade de programas que envolvam universidade e escola básica, por propiciarem o envolvimento de professores em exercício, docentes pesquisadores e estudantes em todos os níveis na busca da melhoria da qualidade de ensino. Por fim, o estudo sugere abertura de mais oportunidades de formação continuada para todos os profissionais da educação, que não se restrinjam a cursos estanques e isolados, mas que sejam frutos de um processo de apropriação téorico-prático com planejamento, acompanhamento e avaliação.

\section{Notas}

${ }^{1}$ Optou-se pela denominação por letras a fim de preservar a identidade dos agentes. 


\section{Referências}

ASBAHR, Flávia da Silva Ferreira. A pesquisa sobre a atividade pedagógica: contribuições da teoria da atividade. Revista Brasileira de Educação, n. 29, p. 108118, maio/ago. 2005. Disponível em:<http://www.scielo.br/pdf/rbedu/n29/n29a09. pdf_> Acesso em: 16 ago. 2017.

COLÉGIO ESTADUAL THIAGO TERRA (PR). Ensino Fundamental e Médio. Projeto político-pedagógico. Londrina, 2011. Disponível em: <http://www.ldathiagoterra. seed.pr.gov.br/redeescola/escolas/18/1380/3280/arquivos/File/ppp.pdf>. Acesso em: 5 maio 2017.

GATTI, Bernadete A. Formação de professores no Brasil: características e problemas. Educação e Sociedade, Campinas, v. 31, n. 113, p. 1355-1379, out./dez. 2010. Disponível em: <http://www.scielo.br/pdf/es/v31n113/16.pdf>. Acesso em: abr. 2017.

GATTI, Bernadete A. A formação inicial de professores para a educação básica: as licenciaturas. Revista USP, São Paulo, n. 100, p. 33-46, dez.2013/fev. 2014. Disponível em: <https://www.revistas.usp.br/revusp/article/view/76164>. Acesso em: 13 ago. 2017.

GIL, Antônio Carlos. Métodos e técnicas de pesquisa social. 6. ed. São Paulo: Atlas, 2008.

LAPO, Flavinês Rebolo; BUENO, Belmira Oliveira. Professores, desencanto com a profissão e abandono do magistério. Cadernos de Pesquisa, São Paulo, n. 118, p. 65-88, mar. 2003. Disponível em: <http://smeduquedecaxias.rj.gov.br/ nead/Biblioteca/Forma\%C3\%A7\%C3\%A30\%20Continuada/Artigos\%20Diversos/ PROFESSORES,\%20DESENCANTO\%20COM\%20A\%20PROFISS\%C3\%830\%20 E\%20ABANDONO\%20DO\%20MAGIST\%C3\%89RIO.pdf>. Acesso em: 13 ago. 2017.

LEONTIEV, Alexis. O homem e a cultura. In: LEONTIEV, Alexis. 0 desenvolvimento do psiquismo. Lisboa: Horizonte, 1978. p. 261-284.

LÜDKE, Menga; ANDRÉ, Marli E. D. A. Abordagens qualitativas de pesquisa: a pesquisa etnográfica e o estudo de caso. In: LÜDKE, Menga; ANDRÉ, Marli E. D. A. Pesquisa em educação: abordagens qualitativas. São Paulo: EPU, 1986. p. 11-24. MARTINS, Lígia Márcia. 0 desenvolvimento do psiquismo e a educação escolar: contribuições à luz da psicologia histórico-cultural e da pedagogia histórico-crítica. Campinas: Autores Associados, 2013. 
MARTINS, Lígia Márcia. A formação social da personalidade do professor: um enfoque vigotskiano. 2. ed. Campinas: Autores Associados, 2015.

SAVIANI, Dermeval. Pedagogia: o espaço da educação na universidade. Cadernos de Pesquisa, São Paulo, v. 37, n. 130, p. 99-134, jan./abr. 2007.

SAVIANI, Dermeval. Pedagogia histórico-crítica: primeiras aproximações. 8. ed. Campinas: Autores Associados, 2003.

SAVIANI, Dermeval. Pedagogia histórico-crítica: primeiras aproximações. 11. ed. Campinas: Autores Associados, 2011.

SAVIANI, Dermeval; DUARTE, Newton (Org.). Pedagogia histórico-crítica e luta de classes na educação escolar. Campinas: Autores Associados, 2012.

SFORNI, Marta Sueli de Faria. Aprendizagem conceitual e organização do ensino: contribuições da teoria da atividade. Araraquara: JM Ed., 2004.

SPIRKIN, Aleksandr Georgievich; YAKHOT, O. Princípios do materialismo histórico. Lisboa: Editorial Estampa, 1975. 